\title{
Inborn errors of metabolism
}

\section{Vitamin-responsive genetic disease}

\author{
S. HARVEY MUDD \\ From the Laboratory of General and Comparative Biochemistry, National Institute of Mental Health, \\ Bethesda, Maryland, USA
}

Vitamin-responsive genetic diseases are currently attracting a good deal of clinical and experimental attention and an effort will be made to review these with emphasis upon two questions: (1) from available evidence and theoretical considerations, what mechanisms underly known instances of vitamin responsiveness? (2) what implications does this knowledge have for improving therapy of these and related diseases?

No attempt will be made to cover the clinical features or to analyse in detail the biochemistry of the diseases discussed. Some of these aspects are covered in several recent reviews of vitaminresponsive (or 'vitamin-dependent') disease(Frimpter, Andelman, and George, 1969; Rosenberg, 1969, 1970; Mudd, 1971; Scriver, 1973) or can be found in the literature cited here. Some of these genetically determined conditions should perhaps more properly be termed 'traits' than 'diseases', since current evidence indicates the biochemical abnormality in at least some persons is not accompanied by clinical disease; for example, cystathioninuria due to cystathionase deficiency (Perry, Hardwick, Hansen, Love, and Israels, 1968b; Scott, Dassell, Clark, Chiang-Teng, and Swedberg, 1970).

In this paper a disease or trait will be considered to be responsive to a vitamin if some of its important and characteristic biochemical manifestations are alleviated by doses of a vitamin larger than that usually regarded as the normal requirement. This biochemical definition leaves open the question of whether the response is beneficial therapeutically. Table I lists those inherited diseases which at present have been shown to be vitamin-responsive. Thus at least 20 genetically determined diseases or biochemical abnormalities are now known to be responsive to one of seven vitamins and since knowledge is expanding rapidly, others may have been inadvertently overlooked. Certainly, there is reason to think that this list will be extended to include additional diseases and vitamins within the next few years.

Patients with a given enzyme deficiency are not uniform in their response to vitamin treatment: some patients respond while others do not. This is one manifestation of genetic heterogeneity and clarification of the basis for the vitamin responsiveness or non-responsiveness will lead to a greater understanding of the molecular variants in the disease. When the potential for vitamin response exists in a disease, each patient may merit a therapeutic trial even if other patients have failed to respond (Scriver, Mackenzie, Clow, and Delvin, 1971).

\section{Mechanisms of Vitamin Responsiveness}

Analysis of the mechanisms involved is favoured by that fact that in 14 of the 20 conditions listed in table I (those indicated) the enzyme or protein abnormality has been established with reasonable certainty and in several of those remaining the presumed abnormality is localized to one of a few potential sites. In all cases the evidence is compatible with the vitamin response being due to an increased flow of metabolite through a reaction for which the vitamin, or one of its metabolites, is either a substrate or a cofactor. Flow through a particular enzyme reaction can be enhanced by two methods: (1) the conditions under which a fixed amount of enzyme is working are changed so that it functions at an increased rate, or (2) the amount of enzyme catalysing the reaction can be changed. Both methods are involved in the known examples of vitamin-responsive disease and will be illustrated by specific examples.

DEFECTIVE METABOLISM OF VITAMINS

The most straightforward situation is a genetic defect in the conversion of a vitamin to its metabolically active form (or forms). This may be a multistep process involving several protein factors and genetically determined abnormalities of these may lead to specific diseases. For example, in the case of cobalamin (vitamin $\mathbf{B}_{12}$ ) several human 


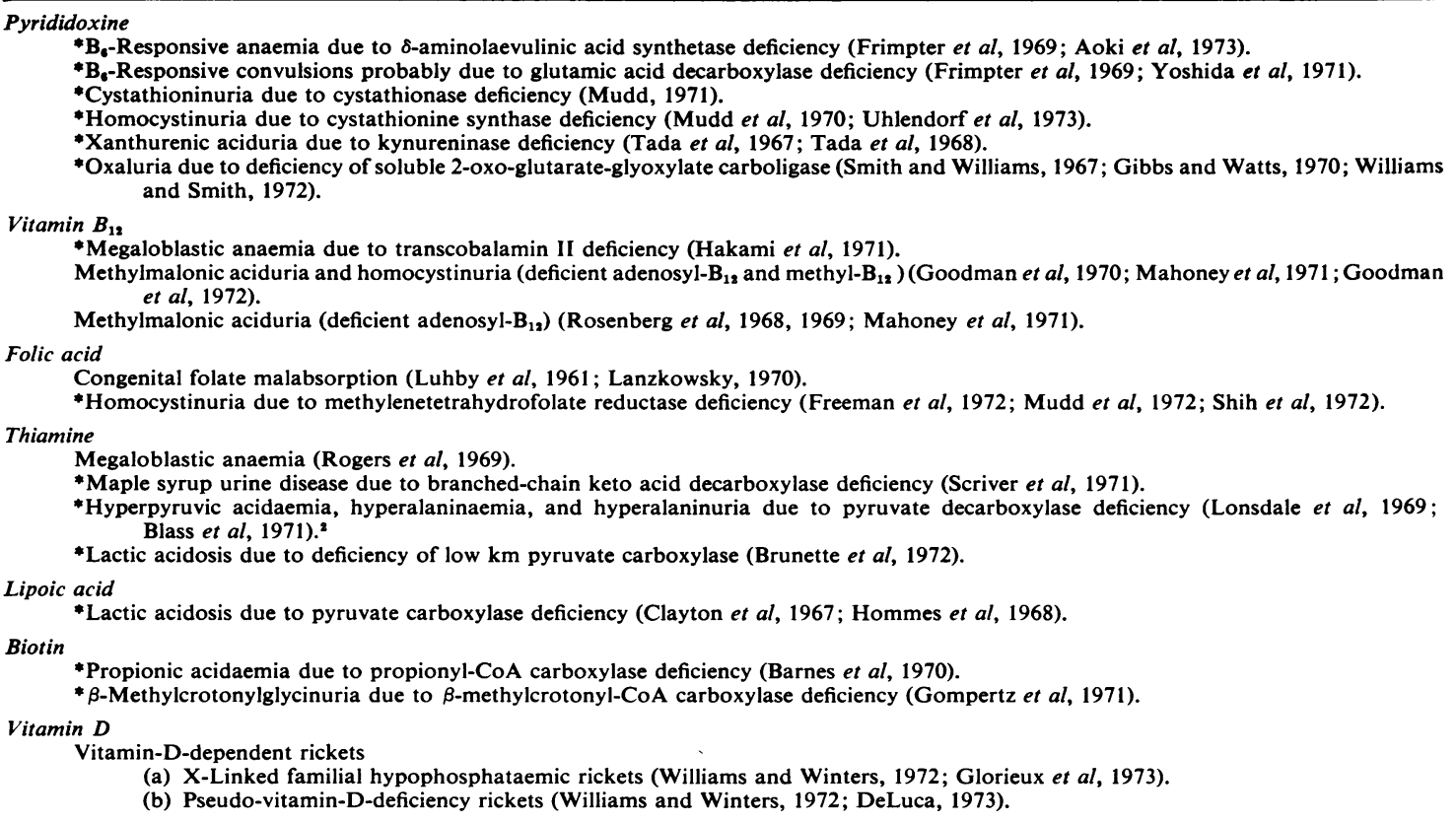

Table I Vitamin-responsive genetic diseases $(1973)^{1}$

${ }^{1}$ Where review articles are cited these should be consulted to determine reporting priority and the sources of original contributions. Diseases in which the underlying protein abnormality is known are indicated by asterisks.

${ }^{2}$ Response to thiamine in reported cases has been equivocal.

mutants are known and the probable or proven abnormalities as listed in table II. The last three of these conditions respond to massive doses of vitamin $B_{12}$ and it is likely that the pathological consequences of the first two might also be $\mathrm{B}_{12}$-responsive (Waife, Jansen, Crabtree, Grinnan, and Fouts, 1963).

These responses can all be explained by a simple model which postulates that a mutant enzyme or transport protein is operating below saturation with respect to its cobalamin substrate (fig 1). Raising the concentration of the substrate by the administration of massive doses of vitamin $\mathbf{B}_{12}$ would then lead to an increased flow through the defective step. In a case of a defective membrane transport process, it is of course, possible that the mutant protein is bypassed and transport occurs by diffusion, or some other less specific mechanism.
Two folic acid-responsive conditions can also be explained by the model illustrated in fig 1 : congenital folate malabsorption and deficiency of methylenetetrahydrofolate reductase, an enzyme which converts one folate derivative to another. The pseudovitamin-D-deficiency form of vitamin-D-dependent rickets may well be another example of vitamin responsiveness brought about by an increase in the concentration of a substrate for a defective enzyme. Recent evidence indicates that this disease may represent a metabolic block in the conversion of 25-hydroxy-vitamin $D_{3}$ to 1,25-dihydroxy-vitamin $D_{3}$ (DeLuca, 1973).

It should be emphasized that although the simple model of a defective protein operating below saturation with its substrate can explain the response in all these abnormalities, there is no direct proof

Congenitally deficient or defective intrinsic factor (Spurling et al, 1964. McIntyre et al, 1965; Katz et al, 1972)

Congenital malabsorption of $\mathrm{B}_{12}$ (ileal factor) (Spurling et al, 1964; Mackenzie et al, 1972).

Transcobalamin I deficiency ${ }^{2}$ (Carmel and Herbert, 1969).

Transcobalamin II deficiency (Hakami et al, 1971).

Failure to accumulate both adenosyl-B $B_{12}$ and methyl-B $B_{12}$ (see table I).

Failure to accumulate adenosyl- $B_{12}$ with normal methyl-B $B_{12}$ (see table $I$ ).

Table II Genetic abnormalities in the handling of vitamin $B_{12}{ }^{1}$

${ }^{1}$ The basis for literature citations is as in table $\mathbf{I}$.

${ }^{2}$ This abnormality is not known to have pathological consequences. 


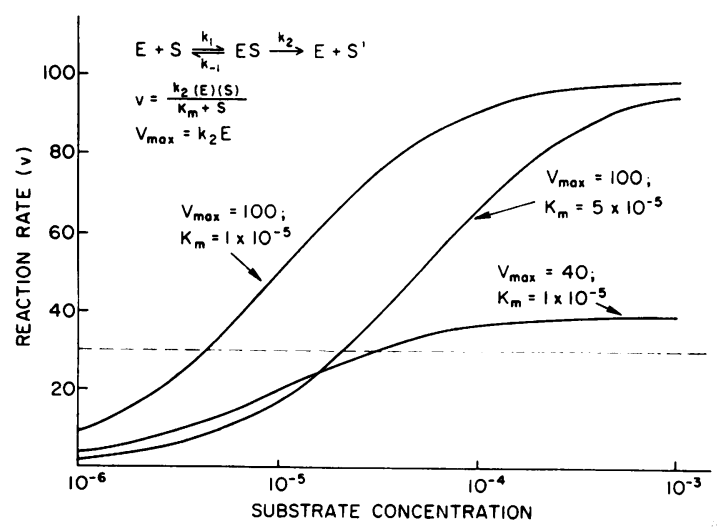

Fig 1 Reaction rate as a function of substrate concentration. Simple Michaelis-Menton kinetics are assumed. The upper curve is for normal enzyme. The other two illustrate the effects of mutations which produce isolated changes in either maximal velocity or $\mathrm{Km}$. The dashed line indicates a rate of product formation which is arbitrarily taken to be physiologically satisfactory.

that this is in fact the operative mechanism. Such proof, when it is attempted, will require as a minimum an examination of the kinetic properties of the altered protein, establishment that under basal conditions substrate is available at a concentration below the $\mathrm{Km}$, and demonstration that the concentration of available substrate is indeed raised by vitamin administration. It is important to realize also that this model may apply to mutant proteins for which either the $\mathrm{Km}$ or the maximal velocity, or both, have been altered (Mudd, 1971). In either case an increase in a non-saturating substrate may possibly achieve a sufficient flow through the reaction in question (fig 1).

In all these situations, the vitamin response takes advantage of the fact that lack of the product formed in the defective reaction, rather than toxicity due to substrate accumulation, accounts for the pathological consequences of improper metabolism of the vitamin. This fact, and the relative non-toxicity of most vitamins, set the conditions for benefit from further increases in substrate concentrations.

DEFECTIVE BINDING OF VITAMIN

\section{COENZYMES TO SPECIFIC APOENZYMES}

At a time when there was little experimental evidence on the mechanisms of vitamin responsiveness, Scriver and Hutchinson (1963) pointed out that inherited modification of coenzyme binding by an apoenzyme might lead to a vitamin-responsive disease if the abnormal interaction could be overcome by relatively high concentrations of cofactor. This mechanism is logically appealing and has since gained widespread acceptance. However, in the opinion of the writer the operation of this mechanism in any specific disorder remains to be established. Experimental evidence suggesting the operation of this mechanism is limited to a very few cases in each of three vitamin $\mathbf{B}_{6}$ responsive diseases. This experimental evidence will first be summarized, and then some of the remaining uncertainties will be discussed.

The results obtained by Tada and coworkers in studies of two unrelated children with vitamin $\mathbf{B}_{\mathbf{6}}$ responsive xanthurenic aciduria due to kynureninase (a pyridoxal-phosphate-dependent enzyme)deficiency are suggestive of the operation of this mechanism (Tada, Yokoyama, Nakagawa, Yoshida, and Arakawa, 1967; Tada, Yokoyama, Nakagawa, and Arakawa, 1968). These authors observed that reaction rates in normal human liver homogenates were increased by $20 \%$ by the addition of the cofactor. Kynureninase activity in liver homogenates of two children with $\mathbf{B}_{6}$-responsive xanthurenic aciduria were quite low in the absence of added pyridoxal phosphate, but when high concentrations of pyridoxal phosphate were added, activity was restored almost to normal. This would certainly be expected if an abnormal interaction between cofactor and mutant enzyme had been overcome by increased cofactor.

Nevertheless, while such evidence makes the suggested mechanism plausible, it falls short of proving that this is actually at work, for several reasons. (1) Alternative, experimentally distinguishable explanations of these data are possible. For example, the mutant enzyme may be abnormally unstable in vitro and undergo rapid inactivation unless high concentrations of cofactor are present (Rosenberg, 1969). (2) No proof has been supplied that the cofactor concentration actually attained in vivo is high enough to support the required rate of catalytic activity. That an increase in vitamin $\mathbf{B}_{6}$ intake may not under some conditions be accompanied by an increase in tissue pyridoxal phosphate concentration is demonstrated by the recent work of Cohen et al (Cohen, Schneidman, Ginsberg-Fellner, Sturman, Knittle, and Gaull, 1973). These workers reported that an increase in the pyridoxine intake of rats from a dose equivalent to the high intake of $150-200 \mathrm{mg}$ daily for a $70-\mathrm{kg}$ man to a dose equivalent to the very high intake of $1500-2000 \mathrm{mg}$ was accompanied by a decrease in pyridoxal phosphate concentration in liver and by no significant change in brain. (3) Before arriving at a final decision as to the prevalent mechanism of vitamin responsiveness in a given disease, it is most desirable to perform kinetic studies of the type performed by Tada and his coworkers on the enzymes from both responsive and non-responsive patients. It will be shown shortly 


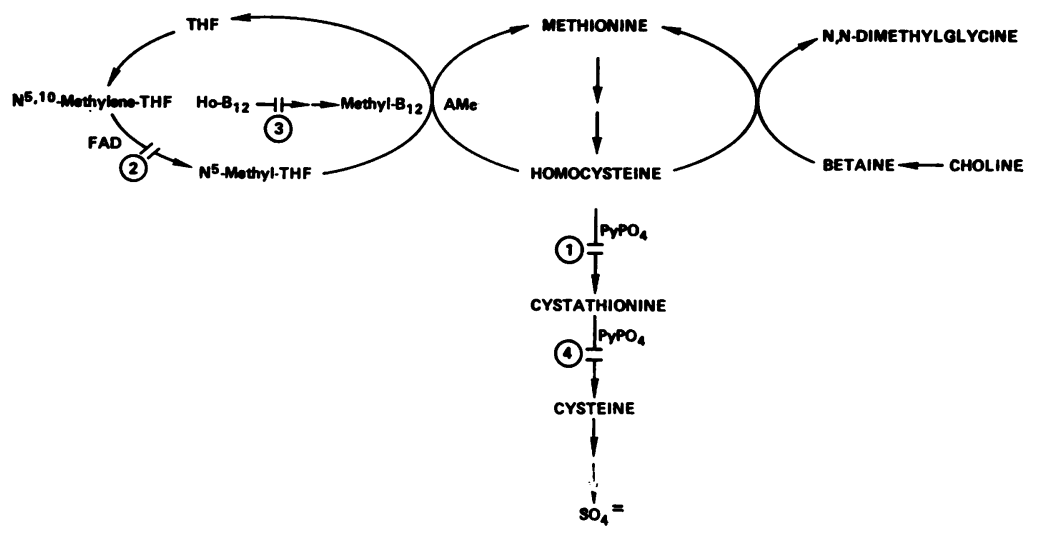

Fig 2 A simplified diagram of the metabolic relationships relevant to cystathionine synthase deficiency and cystathionase deficiency. Cystathionine synthase catalyses reaction 1 . Cystathionase catalyses reaction 4.

that such studies in cases of cystathionase deficiency or cystathionine synthase deficiency may offer valuable and surprising insights into which kinetic properties measured in vitro are constantly associated with clinical responsiveness, and which are not, and may, therefore, be fortuitous.

Altered coenzyme binding has been implicated in cystathioninuria due to $\gamma$-cystathionase deficiency (fig 2). Enzyme assays have been reported for six patients with this relatively rare trait who were clinically responsive to vitamin $B_{6}$ as shown by decreases in plasma and/or urinary cystathionine upon administration of high doses of pyridoxine (Frimpter, Haymovitz, and Horwith, 1963;Mongeau, Hilgartner, Worthen, and Frimpter, 1966; Berlow, 1966; Hooft, Carton, and DeSchryver, 1969). Crude liver extracts from three of these patients were assayed both with and without pyridoxal phosphate added in vitro. The liver extract from one of the patients studied by Frimpter (1965) showed a low $\gamma$-cystathionase activity which was restored almost to normal by the addition of pyridoxal phosphate (approximately $0.38 \mu \mathrm{mol}$ added to an unspecified volume). The extract from a second patient had a low activity which was stimulated approximately four-fold by the addition of cofactor, but remained very low relative to control activities. The low activity in the extract from a third patient, studied by Finkelstein, Mudd, Irreverre, and Laster (1966), was stimulated only slightly by pyridoxal phosphate addition (final concentration $\left.8 \times 10^{-4} \mathrm{~mol} / \mathrm{l}\right)$, as was control $\gamma$-cystathionase activity, and attained a value of only $5 \%$ of the mean control specific activity. The liver extracts from the three siblings studied by Hooft and coworkers (1969) were assayed only in the presence of $5 \times 10^{-5} \mathrm{~mol}$ pyridoxal phosphate/l. The $\gamma$-cystathionase activities were less than $6 \%$ of the mean control value, whether or not the patients were receiving pyridoxine treatment at the time of assay.
Thus, of these six patients, in only one is the evidence compatible with the possibility that the sole abnormality is a binding defect for pyridoxal phosphate which is overcome by a high concentration of that coenzyme. The clinical responses of the other patients must have been based upon one or more other mechanisms. Indeed, in the absence of further evidence it is possible that even the first patient of Frimpter responded by virtue of such an alternative mechanism.

Evidence compatible with altered coenzyme binding has been reported for a single patient with a third condition: vitamin $\mathbf{B}_{6}$-responsive convulsions and decreased renal activity of glutamic decarboxylase. Again, members of the group at Tohoku University found that a low enzyme activity measured in the absence of added cofactor could be restored to normal by in vitro addition of pyridoxal phosphate (Yoshida, Tada, and Arakawa, 1971).

It is of interest to note that the models which suggest that the mutant enzyme is unable to react normally with a cofactor are, in reality, very close to those discussed previously in which the mutant enzyme requires an unusually high substrate concentration to achieve a physiologically satisfactory rate of metabolite flow. In fact, these models may become identical in the case of a cofactor which rapidly equilibrates with the apoenzyme, since such a cofactor is kinetically indistinguishable from a substrate for the enzyme. ${ }^{1}$ In both instances, the beneficial therapeutic effect is attainable because

${ }^{1} \mathrm{~A}$ means of analysing the interaction between an enzyme and a cofactor which associates with it relatively slowly and irreversibly has been described elsewhere (Mudd, 1971). This model may be applicable to most pyridoxal phosphate dependent enzymes. For example, decreased rates of formation of relatively irreversible complexes between mutant apoenzymes and pyridoxal-phosphate would explain the instances of in vitro stimulation of enzyme activities observed with kynureninase, cystathionase, and glutamic decarboxylase and discussed in this section. 
high doses of vitamins and their derivatives can be given and tolerated.

INCREASED STEADY-STATE CONCENTRATION OF ENZYME MUTANT WITH SLIGHT RESIDUAL ACTIVITY

So far instances in which manipulation of the environment of a mutant enzyme results in an increased rate of metabolic flow through the step catalysed by that enzyme have been discussed. An alternative means of increasing such metabolic flow is to change the steady-state concentration of the enzyme itself. Present indications suggest that in most cases of vitamin $B_{6}$-responsive homocystinuria due to cystathionine synthase deficiency (fig 2), this is the operative mechanism. Only some patients with cystathionine synthase deficiency respond to vitamin $\mathbf{B}_{6}$, and, within a sibship, all affected children are either responsive or not, suggesting that responsiveness has a genetic basis (Uhlendorf, Conerly, and Mudd, 1973). Several lines of evidence had already indicated that the vitamin $\mathrm{B}_{6}$-response in this disease is due to an increase in the steady-state concentration of residual cystathionine synthase from a basal level of 1 to $2 \%$ of normal to the relatively modest level of 3 to $4 \%$ of normal. Previously published evidence is summarized as follows (Mudd, Edwards, Loeb, Brown, and Laster, 1970).

1 Changes in plasma and urinary amino acids during vitamin $\mathbf{B}_{6}$ administration are characterized by decreases in homocysteine and its metabolites formed by enzymes proximal to cystathionine synthase, and by an increase in cysteine, the first metabolite measurable distal to the block.

2 No metabolites have been found during vitamin $\mathbf{B}_{6}$ administration to suggest that an alternative pathway for homocysteine disposal has been stimulated.

3 In the few pyridoxine-responsive patients in whom assays of hepatic cystathionine synthase of sufficient sensitivity have been performed before and during vitamin $\mathbf{B}_{6}$ administration, cystathionine synthase activity increased by three- to fourfold, but the activity during pyridoxine treatment is still only 3 to $4 \%$ of the mean control activity.

During the past several years, we have accumulated further results which support this hypothesis and which indicate the quantitative significance of a 1 to $2 \%$ residual activity of cystathionine synthase.

4 There is a striking correlation between clinical responsiveness to vitamin $B_{6}$ and the presence of residual cystathionine synthase activities in extracts of fibroblasts cultured from cystathionine-synthasedeficient patients. Table III summarizes our results on this, and updates the report of Uhlendorf et al (1973). Among responsive sibships, 16 had detectable

\begin{tabular}{lll}
\hline & \multicolumn{2}{l}{$\begin{array}{l}\text { Number of Sibships (or Patients) with } \\
\text { Cystathionine Synthase Activity }\end{array}$} \\
\cline { 2 - 3 } Responsive to Bd & Deted & Notected \\
\cline { 2 - 3 } Not responsive & $2(25)$ & $1(1)$ \\
\hline
\end{tabular}

Table III Residual cystathionine synthase activity and vitamin $B_{6}$-responsiveness

${ }^{1}$ Unbracketed values indicate the number of sibships in each category; bracketed values, the number of individuals.

enzyme activity, ranging from $10 \%$ to $0 \cdot 1 \%$ of the mean control value. One exceptional responsive patient did not have significant cystathionine synthase activity in fibroblast extracts, but had previously been shown to have 1 to $2 \%$ residual activity in her liver (Mudd, Laster, Finkelstein, and Irreverre, 1967). Thus, all responders studied to date have some residual cystathionine synthase activity. On the other hand, among 10 non-responsive sibships, eight had no activity of cystathionine synthase detected by these sensitive assays. Two exceptional non-responders did have activity. Thus, residual cystathionine synthase appears to be a necessary, but not sufficient condition for clinical responsiveness. These results obtained with fibroblast extracts agree with measurements recently reported for liver extracts. Gaull and coworkers did not detect residual cystathionine synthase activities in liver extracts from two vitamin $B_{6}$-unresponsive patients 'before or after $\mathbf{B}_{6}$ '. Two responsive patients in their basal states had hepatic activities of $4 \%$ and $9 \%$ of normal (Gaull, Schaffner, and Sturman, 1973). The need for some residual activity of cystathionine synthase as a precondition of clinical $\mathbf{B}_{6}$-responsiveness offers virtual proof that the $B_{6}$ response is mediated through cystathionine synthase and not by a stimulation of any other enzyme catalysing an alternative pathway for homocysteine disposal.

Studies of the effect in vitro of pyridoxal phosphate addition to the enzyme extracts from patients studied by Uhlendorf et al yielded interesting results. Generally speaking, the addition of pyridoxal phosphate stimulated the residual cystathionine synthase activities of responsive patients only to the same slight extent as occurred with normal enzyme. Surprisingly, a very striking stimulation-at least 10-fold-resulted from the addition of pyridoxal phosphate to the enzyme extract of one of the atypical patients who clinically did not respond to vitamin $B_{6}$ but whose fibroblasts had detectable enzyme activity. The latter finding serves as a warning that stimulation in vitro by a cofactor may not correlate with clinical responsiveness. By implication, when this effect in vitro is seen in a clinically responsive patient, there is still room for doubt whether the 
stimulation is indeed the basis for the responsiveness.

$5 \mathrm{lf}$, as we have suggested, the activity of cystathionine synthase during pyridoxine response may be sufficient to metabolize most of the homocysteine arising from a normal dietary load of methionine, and this activity represents a two- to fourfold enhancement of the activity present in the basal state without vitamin $\mathbf{B}_{6}$ treatment, then $\mathbf{B}_{6}$-responsive patients in their basal states should be capable of metabolizing at least $25-50 \%$ of the normal homocysteine load. This would lead to the daily formation of at least 2-4 mmol of cystathionine, and hence, cysteine in such responsive patients (fig 2 ) and might be reflected by differences in the cystine requirements of vitamin $\mathbf{B}_{6}$-responsive and non-responsive cystathionine-synthase-deficient patients.

To test this prediction we have measured the cystine required to maintain nitrogen balance in cystathionine-synthase-deficient patients in their basal states receiving normal amounts of vitamin $\mathbf{B}_{6}$ (Poole, Mudd, Conerly, and Edwards, 1974). A typical non-responsive patient was in negative nitrogen balance ( $-0.96 \mathrm{~g}$ nitrogen/day) on a daily cystine intake of $155 \mathrm{mg}$, near the lower end of the 'zone of nitrogen equilibrium' ( $-0.38 \mathrm{~g} /$ day) on a cystine intake of $305 \mathrm{mg}$, and in nitrogen balance $(+0.01 \mathrm{~g} /$ day $)$ on a cystine intake of $505 \mathrm{mg}$. These results are comparable with those previously obtained by Brenton, Cusworth, Dent, and Jones (1966) with a $\mathrm{B}_{6}$-non-responsive patient. This patient was in negative balance (approximately $-1.12 \mathrm{~g} /$ day) on a cystine intake of $85 \mathrm{mg}$ and in balance with an intake of 1085. Intermediate cystine intakes were not tested. From these data, a tentative estimate may be made that $300-500 \mathrm{mg}$ of exogenous cystine is required daily for cystathionine-synthase-deficient patients who, being non-responders, are probably without residual activities of the deficient enzyme. The results obtained with vitamin $B_{6}$-responsive patients contrasts with this. None of the four $\mathbf{B}_{6-}$ responsive patients studied had a nitrogen balance significantly below the 'zone of nitrogen equilibrium', even on daily cystine intakes as low as $3-12 \mathrm{mg}$, the lowest intakes which could be achieved on the semisynthetic diets used for these experiments. We conclude that these patients can form, endogenously from methionine, at least $300-500 \mathrm{mg}$ daily or
$2 \cdot 5-4 \cdot 2 \mathrm{mmol}$ of cysteine. These amounts are roughly equivalent to $25-50 \%$ of the normal intake of methionine. Therefore, we regard these studies as strongly supporting the hypothesis that small residual activities of cystathionine synthase- $1-2 \%$ of normal - may contribute metabolic capacities which are significant relative to the normal daily load. If such residual activities are enhanced (for example, by vitamin $B_{6}$ treatment) it then becomes reasonable to suppose that the normal load of homocysteine could be handled without undue accumulation of metabolites proximal to the block.

The mechanism whereby pyridoxine brings about this increase has not been established. We have shown that the cystathionine synthase of both control subjects and deficient patients is stabilized to heat inactivation by pyridoxal phosphate (Mudd et al, 1970). There is increasing evidence that inactivation of enzymes occurs chiefly in the apoenzyme form (see, for example, Litwack and Rosenfield, 1973, and literature cited there). Pyridoxine may then act by stabilizing mutant cystathionine synthase in vivo but other mechanisms are certainly possible.

Another possible example of a vitamin $\mathrm{B}_{6}$ response due to a small increase in residual enzyme activity is suggested by a recent study of a single patient with primary pyridoxine-responsive sideroblastic anaemia and deficient $\delta$-aminolaevulinic acid synthetase activity (Aoki, Urata, and Takaku, 1973). The synthetase activity in extracts of erythroblasts of this patient, assayed in the presence of added pyridoxal phosphate, increased from $4 \%$ of the mean control value when the patient was in his basal state to $10 \%$ of the mean control value after one month's treatment with pyridoxal phosphate.

\section{BENEFIT OF SMALL INCREASES IN}

ALREADY-LOW ENZYME ACTIVITIES

These studies of vitamin $\mathbf{B}_{6}$-responsive cystathionine synthase deficiency and $\delta$-aminolaevulinic acid synthetase deficiency demonstrate that it may be possible to produce a response by increasing the steady-state concentration of a mutant enzyme to a level which is still very low compared with the normal. That this situation may not be exceptional is shown by experience with variant forms of many genetic diseases. Thus table IV shows that patients with two different lipidoses, those with $12-44 \%$ of normal

\begin{tabular}{lcl}
\hline Enzyme & Proportion of Normal Activity (\%) & Disorder \\
\hline Glucocerebrosidase & $0-9$ & Classical infantile Gaucher's disease \\
Sphingomyelinase & $12-44$ & Adult form of Gaucher's disease \\
& $0-7$ & Infantile form of Niemann-Pick disease \\
& $15-20$ & Adult form of Niemann-Pick disease
\end{tabular}

Table IV Enzyme activities and phenotypic expression in lipid storage diseases (adapted from Brady, 1973) 


\begin{tabular}{|c|c|c|c|}
\hline $\begin{array}{l}\text { Proportion of Normal } \\
\text { Activity }(\%)\end{array}$ & Dietary Protein Tolerance & Diet Required & Clinical Characteristics \\
\hline $0-2$ & $\begin{array}{l}\text { Inadequate to maintain } \\
\text { nitrogen balance }\end{array}$ & $\begin{array}{l}\text { Chiefly purified amino acids, low } \\
\text { in branched-chain amino acids }\end{array}$ & Severe symptoms in first weeks of life \\
\hline $2-8$ & $1 \cdot 5-2 \mathrm{~g} / \mathrm{kg}$ & Low protein & $\begin{array}{l}\text { Symptoms often delayed and intermittent, } \\
\text { induced by high protein intake or stress }\end{array}$ \\
\hline
\end{tabular}

Table V Branched-chain keto acid decarboxylase activities and phenotypic expression (adapted from Zaleski et al, 1973)

\begin{tabular}{ll}
\hline Proportion of Normal Enzyme Activity (\%) & Characteristics \\
\hline Mostly $<0.1(<0.004$ to 94$)$ & $\begin{array}{l}\text { Hyperuricaemia and hyperuric aciduria } \\
\text { Self mutilation }\end{array}$ \\
& $\begin{array}{l}\text { Choreoathetosis } \\
\text { Retarded mental and physical development }\end{array}$ \\
Mostly $>0.1(0.01$ to 32$)$ & Hyperuricaemia and hyperuric aciduria \\
& Gout
\end{tabular}

Table VI Hypoxanthine-guanine phosphoribosyltransferase activities and phenotypic expression (adapted from Kelley and Arnold, 1973)

activity of the defective enzyme, are much less severely affected than those with $0-9 \%$. In table $\mathrm{V}$, residual activities of branched-chain keto acid decarboxylase are correlated with the clinical manifestations in variant forms of maple-syrup urine disease. An increase of this enzyme from $2 \%$ of normal to somewhat more than $8 \%$ transforms a severe life-threatening disease into a situation in which symptoms appear intermittently, if at all. Among the amino acidopathies, the presence of as little as 5 to $7 \%$ of normal phenylalanine hydroxylase activity prevents almost all the usual clinical difficulties associated with classical phenylketonuria (Kang, Kaufman, and Gerald, 1970; Friedman, Kaufman, and Kang, 1972). Finally, as shown in table VI, among patients with various lesions of hypoxanthine-guanine phosphoribosyltransferase, in most cases the possession of as little as $0.1 \%$ of normal activity is sufficient to prevent the most severe manifestations of the Lesch-Nyhan syndrome. However, the overlap in residual activities between patients with these differing clinical manifestations of hypoxanthine-guanine phosphoribosyltransferase deficiency emphasizes that the situation is really more complex than can be ascertained by a measurement of residual enzyme activity in a single cell type under one set of experimental conditions. Differences with respect to stability, kinetic properties, product inhibition, and so on may all play a role. As these differences are explored fully, relatively clear-cut distinctions such as those just made between cystathionine-synthase deficient- $\mathrm{B}_{6}$-responders and non-responders, and in tables IV-VI, can fade. A good example is afforded by studies of glucose-6phosphate dehydrogenase variants (Kirkman, 1971). Nevertheless, it does appear that, as a general rule, a small amount of residual enzyme activity may be very beneficial. Conversely any therapeutic intervention which leads to this being enhanced, even to a slight extent only, may well be of great benefit.

ENHANCEMENT OF ALTERNATIVE PATHWAYS In the instances considered so far, vitamin administration increases metabolite flow through a step which has been rendered inadequate because of a mutant protein. However, in several known instances of vitamin-responsive disease, it appears that the vitamin acts by stimulating flow through an alternative pathway catalyzed by a normal enzyme. Thus in lactic acidosis due to deficiency of the low $\mathrm{Km}$ pyruvate carboxylase, a decrease in accumulated lactate and alanine occurred after large doses of thiamine (Brunette, Delvin, Hazel, and Scriver, 1972). Thiamine pyrophosphate is not known to be a cofactor for the defective enzyme, pyruvate carboxylase, but is a cofactor for another enzyme which disposes of pyruvate, namely, pyruvate dehydrogenase (fig 3). Adding thiamine to the medium enhanced flow through the dehydrogenase step in assays with intact peripheral leucocytes from both control subjects and the patient with pyruvate carboxylase deficiency. Presumably a similar effect accounts for the clinical response to thiamine (Brunette et al, 1972).

The response to lipoic acid of some cases of a closely related disease, due to an almost complete 


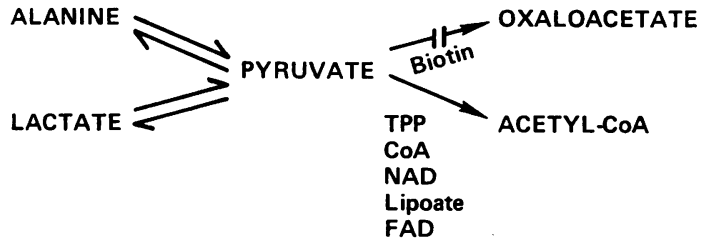

Fig 3 A simplified diagram of the metabolic relationships pertinent to thiamine- or lipoic acid-responsive pyruvate carboxylase deficiency. Pyruvate carboxylase catalyses the conversion of pyruvate to oxaloacetate. Pyruvate decarboxylase (dehydrogenase) catalyses the conversion of pyruvate to acetyl-CoA.

absence of pyruvate carboxylase activity, may be analogous (Clayton, Dobbs, and Patrick, 1967; Hommes, Polman, and Rerrink, 1968). Another example is the response to pyridoxine of some cases of primary oxaluria due to deficient activity of soluble 2-oxo-glutarate-glyoxylate carboligase (Gibbs and Watts, 1970; Williams and Smith, 1972). In these cases it is thought that vitamin $\mathbf{B}_{6}$ enhances the removal of accumulated glyoxylate by increasing flow through a pyridoxal-phosphate-dependent transaminase which catalyses the conversion of glyoxylate to glycine (fig 4). In none of these cases in which a normal enzyme activity is presumably enhanced by vitamin administration has the immediate mechanism by which the enzyme activity is affected been defined. One or more of the mechanisms discussed earlier in this paper may play a role.

The extent to which any of these manoeuvres is truly therapeutic must ultimately be evaluated in terms of clinical benefit to the patient. Situations in which a vitamin response is mediated through an effect on a normal, rather than a mutant, enzyme deserve particularly close scrutiny from this point of view, since in these situations intervention does not directly alleviate the primary abnormality, but introduces a second compensatory change from normal. In some instances the acute clinical benefit to the individual patient speaks for itself, as in the

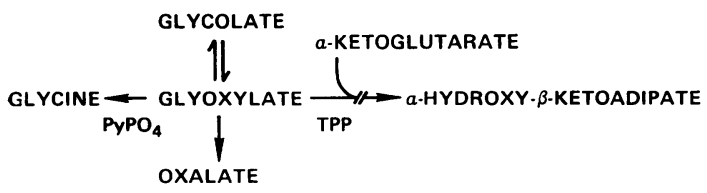

Fig 4 A simplified diagram of the metabolic relationships pertinent to pyrodoxine-responsive oxaluria due to deficiency of 2-oxo-glutarate-glyoxylate carboligase. The later enzyme catalyses the conversion of glyoxylate to a-hydroxy- $\beta$-ketoadipate. A transaminase catalyses the conversion of glyoxylate to glycine. case of thiamine-responsive lactic acidosis reported by Brunette and colleagues (Brunette et al, 1972). Even in this case, the effect of attempts to restore metabolic flow through the primarily defective pyruvate carboxylase by treatment with biotin, the cofactor for this enzyme, remains to be evaluated (Brunette et al, 1972). In other, more chronic, diseases evaluation of the worth of a vitamin treatment may pose real difficulties. For example, the homocyst(e)ine accumulation which is the immediate result of cystathionine synthase deficiency may be decreased by treatment with folic acid (Carey, Fennelly, and Fitzgerald, 1968; Morrow and Barness, 1972), choline (Perry, Hansen, Love, Crawford, and Tischler, 1968a), or betaine (Komrower and Sardharwalla, 1971). During these treatments decreases in plasma and urinary homocyst(e)ine are usually accompanied by rises in methionine, as would be expected if remethylation of homocysteine had been enhanced (fig 2). Whether this alteration in the distribution of accumulated compounds is beneficial or not depends upon the extent to which homocyst(e)ine, on the one hand, or methionine on the other, accounts for the pathological consequences of cystathionine synthase deficiency. There are some indications that homocysteine is the chief toxic metabolite (McCully, 1970; McCully and Ragsdale, 1970; Kang and Trelstad, 1973), but the evidence is hardly adequate to permit more than a tentative judgment to be made.

\section{Summary}

The several ways in which vitamin administration may bring about a biochemical response in genetic abnormalities have been discussed. Two major interrelated lessons emerge from what we now know about vitamin-responsive genetic disease. First, it is possible to enhance metabolite flow through partially deficient reactions by suitable manipulation of the environment in which a fixed amount of enzyme functions or by changing the concentration of the enzyme itself. The latter approach may be the most versatile in the long run since there may be agents other than vitamins which increase enzyme concentrations. A striking example of such an effect in mammals is furnished by the work of Pitot and his collaborators, who by administration of casein hydrolysate to rats, increased threonine dehydratase activity several hundred-fold (Peraino and Pitot, 1964) by increasing the rate of enzyme synthesis (Jost, Khairallah, and Pitot, 1968). Other means of enhancing enzyme activities, ranging from tissue transplantation to transfer of genetic material, have been discussed elsewhere (for example, see Brady, 1973). 
These procedures will not be discussed here, other than to mention a recent report (Mukherjee and Krasner, 1973) who transferred several small plugs of liver tissue (approximately $5 \%$ of the liver) from normal rats to the livers of rats genetically deficient in bilirubin uridinediphosphate glucuronyltransferase activity. Twelve weeks later the specific activity of glucuronyltransferase had risen in the livers of the recipient rats to $6-23 \%$ of normal, and the serum bilirubin of these rats, which had initially been elevated, had fallen to close to, or within, the normal range. Thus liver grafts between suitably matched individuals, may in the near future, become a means of increasing hepatic activities of deficient enzymes to extents which are therapeutically meaningful.

The second lesson to be learned from the review presented here is that enhancement of enzyme activity may be therapeutically beneficial even though the increase is small and the activity attained is still reduced relative to normal. It will be well to bear this in mind in any attempts to treat inborn errors of metabolism.

\section{References}

Aoki, Y., Urata, G., and Takaku, F. (1973). $\delta$-Amino levulinic acid synthetase activity in erythroblasts of patients with primary sideroblastic anaemia. Acta haemat. jap., 86, 74-77.

Barnes, N. D., Hull, D., Balgobin, L., and Gompertz, D. (1970). Biotin-responsive propionicacidaemia. Lancet, 2, 244-245.

Berlow, S. (1966). Studies in cystathioninemia. Amer. J. Dis. Child., $112,135-142$.

Blass, J. P., Lonsdale, D., Uhlendorf, B. W., and Hom, E. (1971). Intermittent ataxia with pyruvate-decarboxylase deficiency. Lancet, 1, 1302.

Brady, R. O. (1973). The abnormal biochemistry of inherited disorders of lipid metabolism. Fed. Proc., 32, 1660-1667.

Brenton, D. P., Cusworth, D. C., Dent, C. E., and Jones, E. E. (1966). Homocystinuria: clinical and dietary studies. Quart. J. Med., 35, 325-346.

Brunette, M. G., Delvin, E., Hazel, B., and Scriver, C. R. (1972). Thiamine-responsive lactic acidosis in a patient with deficient low-Km pyruvate carboxylase activity in liver. Pediatrics, 50, 702-711.

Carey, M. C., Fennelly, J. J., and Fitzgerald, O. (1968). Homocystinuria. II. Subnormal serum folate levels, increased folate clearance and effects of folic acid therapy. Amer. J. Med., 45, 26-31.

Carmel, R., and Herbert, V. (1969). Deficiency of vitamin $B_{12}$-binding alpha globulin in two brothers. Blood, 33, 1-12.

Clayton, B. E., Dobbs, R. H., and Patrick, A. D. (1967). Leigh's subacute necrotizing encephalopathy: clinical and biochemical study, with special reference to therapy with lipoate. Arch. Dis. Child., 42, 467-478.

Cohen, P. A., Schneidman, K., Ginsberg-Fellner, F., Sturman, J. A., Knittle, J., and Gaull, G. E. (1973). High pyridoxine diet in the rat: possible implications for megavitamin therapy. J. Nutr., $103,143-151$.

DeLuca, H. F. (1973). The kidney as an endocrine organ for the production of 1,25-dihydroxy-vitamin $\mathrm{D}_{3}$, a calcium-mobilizing hormone. New Engl. J. Med., 289, 359-365.

Finkelstein, J. D., Mudd, S. H., Irreverre, F., and Laster, L. (1966). Deficiencies of cystathionase and homoserine dehydratase activities in cystathioninuria. Proc. nat. Acad. Sci. (Wash.), 55, 865-872.

Freeman, J. M., Finkelstein, J. D., Mudd, S. H., and Uhlendorf, B. W. (1972). Homocystinuria presenting as reversible 'schizophrenia': a new defect in methionine metabolism with reduced methylene-tetrahydrofolate-reductase activity. (Abstr.) Pediat. Res., 6, 423.

Friedman, P. A., Kaufman, S., and Kang, E. S. (1972). Nature of the molecular defect in phenylketonuria and hyperphenylalaninaemia. Nature (Lond.), 240, 157-159.

Frimpter, G. W. (1965). Cystathioninuria: nature of the defect. Science, 149, 1095-1096.

Frimpter, G. W., Haymovitz, A., and Horwith, M. (1963). Cystathioninuria. New Engl. J. Med., 268, 333-339.

Frimpter, G. W., Andelman, R. J., and George, W. F. (1969). Vitamin $B_{a}$-dependency syndromes. Amer. J. clin. Nutr., 22, 794-805.

Gaull, G. E., Schaffner, F., and Sturman, J. A. (1973). Cystathionine synthase deficiency: enzymatic and ultrastructural studies of liver from heterozygotes and from homozygotes treated with pyridoxine. (Abstr.) Pediat. Res., 7, 347.

Gibbs, D. A., and Watts, R. W. E. (1970). The action of pyridoxine in primary hyperoxaluria. Clin. Sci., 38, 277-286.

Glorieux, F. H., Scriver, C. R., Holick, M. F., and DeLuca, H. F. (1973). X-Linked hypophosphataemic rickets: inadequate therapeutic response to 1,25-dihydroxycholecalciferol. Lancet, 2, 287-289.

Gompertz, D., Draffan, G. H., Watts, J. L., and Hull, D. (1971). Biotin-responsive $\beta$-methylcrotonyl-glycinuria. Lancet, 2, 22-24.

Goodman, S. I., Keyser, A. J., Mudd, S. H., Schulman, J. D., Turse, H., and Lewy, J. (1972). Responsiveness of congenital methylmalonic aciduria to derivations of vitamin $\mathbf{B}_{12}$. (Abstr.) Pediat. Res., 6, 398.

Goodman, S. I., Moe, P. G., Hammond, K. B., Mudd, S. H., and Uhlendorf, B. W. (1970). Homocystinuria with methylmalonic aciduria: two cases in a sibship. Biochem. Med., 4, 500-515.

Hakami, N., Neiman, P. E., Canellos, G. P., and Lazerson, J. (1971). Neonatal megaloblastic anemia due to inherited transcobalamin II deficiency in two siblings. New Engl. J. Med., 285, 1163-1170.

Hommes, F. A., Polman, H. A., and Reerink, J. D. (1968). Leigh's encephalomyelopathy: an inborn error of gluconeogenesis. Arch. Dis. Childh., 43, 423-426.

Hooft, C., Carton, D., and DeSchryver, F. (1969). Cystathioninemia in three siblings. In Enzymopenic Anaemias, Lysosomes and Other Papers. Proceedings of the Sixth Symposium of the Society for the Study of Inborn Errors of Metabolism, edited by J. D. Allan, K. S. Holt, J. T. Ireland, and R. J. Pollitt, pp. 200-207. Livingstone, Edinburgh and London.

Jost, J. P., Khairallah, E. A., and Pitot, H. C. (1968). Studies on the induction and repression of enzymes in rat liver. V. Regulation of the rate of synthesis and degradation of serine dehydratase by dietary amino acids and glucose. J. biol. Chem., 243, 3057-3066.

Kang, A. H., and Trelstad, R. L. (1973). A collagen defect in homocystinuria. J. clin. Invest., 52, 2571-2578.

Kang, E. S., Kaufman, S., and Gerald, P. S. (1970). Clinical and biochemical observations of patients with atypical phenylketonuria. Pediatrics, 45, 83-92.

Katz, M. Lee, S. K., and Cooper, B. A. (1972). Vitamin B $B_{12}$ malabsorption due to a biologically inert intrinsic factor. New Engl. J. Med., 287, 425-429.

Kelley, W. N., and Arnold, W. J. (1973). Human hypoxanthineguanine phosphoribosyltransferase: studies on the normal and mutant forms of the enzyme. Fed. Proc., 32, 1656-1659.

Kirkman, H. N. (1971). Glucose-6-phosphate dehydrogenase. Advanc. hum. Genet., 2, 1-60.

Komrower, G. M., and Sardharwalla, I. B. (1971). The dietary treatment of homocystinuria. In Inherited Disorders of Sulphur Metabolism, edited by N. A. J. Carson and D. N. Raine pp. 254-263. Churchill Livingstone, Edinburgh and London.

Lanzkowsky, P. (1970). Congenital malabsorption of folate. Amer. J. Med., 48, 580-583.

Litwack, G., and Rosenfield, S. (1973). Coenzyme dissociation, a possible determinant of short half-life of inducible enzymes in mammalian liver. Biochem. biophys. Res. Commun., 52, 181-188.

Lonsdale, D., Faulkner, W. R., Price, J. W., and Smeby, R. R. (1969). Intermittent cerebellar ataxia associated with hyperpyruvic acidemia, hyperalaninemia, and hyperalaninuria. Pediatrics, 43, 1025-1034.

Luhby, A. L., Eagle, F. J., Roth, E., and Cooperman, J. M. (1961). Relapsing megaloblastic anemia in an infant due to a specific defect in gastrointestinal absorption of folic acid. Amer. J. Dis. Child., 102, 482-483. 
McCully, K. S. (1970). Importance of homocysteine-induced abnormalities of proteoglycan structure in arteriosclerosis. Amer. J. Path., 59, 181-193.

McCully, K. S., and Ragsdale, B. D. (1970). Production of arteriosclerosis by homocysteinemia. Amer. J. Path., 61, 1-8.

McIntyre, O. R., Sullivan, L. W., Jeffries, G. H., and Silver, R. H. (1965). Pernicious anemia in childhood. New Engl. J. Med., 272, 981-986.

Mackenzie, I.L., Donaldson, R. M., Jr., Trier, J. S. and Mathan, V. I. (1972). Ileal mucosa in familial selective vitamin $B_{12}$ malabsorption. New Engl. J. Med., 286, 1021-1025.

Mahoney, M. J., Rosenberg, L. E., Mudd, S. H., and Uhlendorf, B. W. (1971). Defective metabolism of vitamin $\mathbf{B}_{12}$ in fibroblasts from children with methylmalonicaciduria. Biochem. biophys. Res. Commun., 44, 375-381.

Mongeau, J. G., Hilgartner, M., Worthen, H. G., and Frimpter, G. W. (1966). Cystathioninuria: study of an infant with normal mentality, thrombocytopenia, and renal calculi. J. Pediat., 69, 1113-1120.

Morrow, G., III, and Barness, L. A. (1972). Combined vitamin responsiveness in homocystinuria. J. Pediat., 81, 946-954.

Mudd, S. H. (1971). Pyridoxine-responsive genetic disease. Fed. Proc., 30, $970-976$.

Mudd, S. H., Edwards, W. A., Loeb, P. M., Brown, M. S., and Laster, L. (1970). Homocystinuria due to cystathionine synthase deficiency: the effect of pyridoxine.J. clin. Invest., 49, 1762-1173.

Mudd, S. H., Laster, L., Finkelstein, J. D., and Irreverre, F. (1967). Studies on homocystinuria. In Amines and Schizophrenia, edited by H. E. Himwich, S. S. Kety, and J. R. Smythies, pp. 247-256. Pergamon Press, Oxford.

Mudd, S. H., Uhlendorf, B. W., Freeman, J. M., Finkelstein, J. D., and Shih, V. E. (1972). Homocystinuria associated with decreased methylenetetrahydrofolate reductase activity. Biochem. biophys. Res. Commun., 46, 905-912.

Mukherjee, A. B., and Krasner, J. (1973). Induction of an enzyme in genetically deficient rats after grafting of normal liver. Science, $182,68-70$.

Peraino, C., and Pitot, H. C. (1964). Studies on the induction and repression of enzymes in rat liver. II. Carbohydrate repression of dietary and hormonal induction of threonine dehydrodase and ornithine $\delta$-transaminase. J. biol. Chem., 239, 4308-4313.

Perry, T. L., Hansen, S., Love, D. L., Crawford, L. E., and Tischler, B. (1968a). Treatment of homocystinuria with a low-methionine diet, supplemental cystine, and a methyl donor. Lancet, 2 , 474-478.

Perry, T. L., Hardwick, D. F., Hansen, S., Love, D. L., and Israels, S. (1968b). Cystathioninuria in two healthy siblings. New Engl. J. Med., 278, 590-592.

Poole, J., Mudd, S. H., Conerly, E. B., and Edwards, W. A. (1974). Homocystinuria due to cystathionine synthase deficiency: studies of nitrogen balance and sulfur excretion. In preparation for publication

Rogers, L. E., Porter, F. S., and Sidbury, J. B., Jr. (1969). Thiamineresponsive megaloblastic anemia. J. Pediat., 74, 494-504.

Rosenberg, L. E. (1969). Inherited aminoacidopathies demonstrating vitamin dependency. New Engl. J. Med., 281, 145-153.
Rosenberg, L. E. (1970). Vitamin-dependent genetic disease. Hosp. Pract., 5, 59-67.

Rosenberg, L. E., Lilljeqvist, A. C., and Hsia, Y. E. (1968). Methylmalonic aciduria: metabolic block localization and vitamin $\mathbf{B}_{18}$ dependency. Science, 162, 805-807.

Rosenberg, L. E., Lilljeqvist, A. C., Hsia, Y. E., and Rosenbloom, F. M. (1969). Vitamin $B_{12}$ dependent methylmalonicaciduria: defective $\mathbf{B}_{12}$ metabolism in cultured fibroblasts. Biochem. biophys. Res. Commun. 37, 607-614.

Scott, C. R., Dassell, S. W., Clark, S. H., Chiang-Teng, C., and Swedberg, K. R. (1970). Cystathioninemia: a benign genetic condition. J. Pediat., 76, 571-577.

Scriver, C. R. (1973). Vitamin-responsive inborn errors of metabolism. Metabolism, 22, 1319-1344.

Scriver, C. R., and Hutchison, J. H. (1963). Vitamin $B_{6}$ deficiency syndrome in human infancy. In Yearbook of Pediatrics, 19631964 Series, edited by S. S. Gellis, pp. 45-48. Year Book Medical Publishers, Chicago, Illinois.

Scriver, C. R., Mackenzie, S., Clow, C. L., and Delvin, E. (1971). Thiamine-responsive maple-syrup-urine disease. Lancet, 1 , 310-312.

Shih, V. E., Salam, M. Z., Mudd, S. H., Uhlendorf, B. W., and Adams, R. D. (1972). A new form of homocystinuria due to $\mathrm{N}^{\mathrm{s} 10}$-methylene tetrahydrofolate reductase deficiency. (Abstr.) Pediat. Res., 6, 395.

Smith, L. H., Jr., and Williams, H. E. (1967). Treatment of primary hyperoxaluria. Modern Treatment, 4, 522-530.

Spurling,C. L., Sacks, M. S., and Jiji, R. M. (1964). Juvenile pernicious. anemia. New Engl. J. Med., 271, 995-1003.

Tada, K., Yokoyama, Y., Nakagawa, H., Yoshida, T., and Arakawa, T. (1967). Vitamin $\mathbf{B}_{6}$ dependent xanthurenic aciduria. Tohoku J. exp. Med., 93, 115-124.

Tada, K., Yokoyama, Y., Nakagawa, H., and Arakawa, T. (1968). Vitamin $B_{6}$ dependent xanthurenic aciduria (the second report). Tohoku J. exp. Med., 95, 107-114.

Uhlendorf, B. W., Conerly, E. B., and Mudd, S. H. (1973). Homocystinuria: studies in tissue culture. Pediat. Res., 7, 645-658.

Waife, S. O., Jansen, C. J., Crabtree, R. E., Grinnan, E. L., and Fouts P. J. (1963). Oral vitamin $B_{12}$ without intrinsic factor in the treatment of pernicious anemia. Ann. intern. Med., 58, 810-817.

Williams, H. E., and Smith, L. H., Jr. (1972). Primary hyperoxaluria. In The Metabolic Basis of Inherited Disease, edited by J. B. Stanbury, J. B. Wyngaarden, and D. S. Fredrickson, 3rd ed., pp. 196-219. McGraw-Hill, New York.

Williams, T. F. and Winters, R. W. (1972). Familial (hereditary) vitamin D-resistant rickets with hypophosphatemia. In The Metabolic Basis of Inherited Disease, edited by J. B. Stanbury, J. B. Wyngaarden, and D. S. Fredrickson, 3rd ed., pp. 14651485, McGraw-Hill, New York.

Yoshida, T., Tada, K., and Arakawa, T. (1971). Vitamin B -deficiency $^{-}$ of glutamic acid decarboxylase in the kidney from a patient with vitamin $\mathrm{B}_{6}$ dependent convulsion. Tohoku J. exp. Med., 104, 195-198.

Zaleski, L. A., Dancis, J., Cox, R. P., Hutzler, J., Zaleski, W. A., and Hill, A. (1973). Variant maple syrup urine disease in mother and daughter. Canad. med. Ass. J., 109, 299-304. 